\title{
Model for Assessment of Agile Methodology for Implementing Data Warehouse Projects
}

\author{
Kuldeep Deshpande \\ Ellicium Solutions \\ Kothrud \\ Pune
}

\author{
Bhimappa Desai, PhD \\ Capgemini \\ Nanded City \\ Pune
}

\begin{abstract}
Use of Agile methodologies for datawarehouse project implementation has been recommended in last few years considering challenges with using waterfall methodologies. This paper examines factors that decide suitability of agile methodology for datawarehouse projects. It proposes a model for assessing projects on various factors to decide if agile methodology is suitable for a datawarehouse project. This research contributes to IS success theory in the field of datawarehousing. Practical evaluation and application of model to projects can lead to avoiding high cost failures of datawarehouse projects.
\end{abstract}

\section{General Terms}

Datawarehouse, Software Engineering

\section{Keywords}

Agile, AHP

\section{INTRODUCTION}

Datawarehouse projects are characterized by high rate of failure, high capital investment and hence are very risky endeavors. Past research [14] has discussed limitations and challenges of using traditional software development life cycle techniques for development of datawarehouse. Various authors $[9,15,17,18]$ have proposed use of Agile methodologies for datawarehouse development. Studies $[4,5]$ have indicated that use of agile methodology increases the chances of success in datawarehouse development. However use of agile methodologies for datawarehouse projects does not guarantee success. Failure of datawarehouse projects using agile methodology have been reported [19]. Hence it becomes imperative to study factors that decide whether agile methodology is suitable for a datawarehouse project or not. Previous studies [1,2] regarding assessment of suitability of agile methods were generic and not focused on any type of software projects. This study proposes a model for assessment of agile methodologies for implementing datawarehouse projects. Analytical Hierarchy Process (AHP) has been used to analyze various factors impacting decision of selection of methodology for a datawarehouse project.

This work is organized as follows: In section 2, challenges in using traditional waterfall methodologies for datawarehouse development have been reviewed. In section 3 option of using agile methodologies is discussed. The objectives of this study have been formulated in section 4 . To formulate a model to decide suitability of agile methodology, first important step is to decide factors that dictate methodology to be used for a project. In section 5 all possible factors have been discussed a have been shortlisted for this study. Actual AHP model has been constructed in section 6. Model developed in this study has been analyzed in section 7 . In section 8 the model has been applied to case studies of past datawarehouse projects. Finally in section 9 directions for future research have been specified.

\section{CHALLENGES IN TRADITIONAL TECHNIQUES OF DATA WAREHOUSE DEVELOPMENT}

In [13] reasons of why a DW project has different and higher risk compared to transactional projects are described. According to this paper:

- DW projects have greater complexity of data but simpler processes.

- DW projects are used by more senior and demanding stakeholders.

- Learning and discovery can alter projects' priorities and scope

- A high risk that users will circumvent the DW system and continue using their traditional data sources for decision making.

In [14] a study of traditional techniques of datawarehousing and their limitations is provided. Key elements of Agile BI are discussed in [7]. A summary of key limitations of traditional datawarehousing techniques is as below:

- Long upfront requirement phase not providing any input to design

- Long times between system request and delivery

- Users are not involved in design, development and most importantly testing

- Very little and isolated focus on non-functional requirements and lack of methodologies for testing of datawarehouse.

- Lack of flexibility and acceptance to changing requirements

- Inadequate testing due to large data volumes.

- Lack of standard testing process for datawarehouse testing

\section{AGILE METHODOLOGY FOR DATAWAREHOUSE PROJECTS}

From above discussion, it is clear that long development cycles, delays in getting working BI product to users, lack of involvement of business users in phases beyond requirement and unresponsiveness to changes are major limitations of traditional datawarehousing techniques. 
Agile processes focus on facilitating early and fast production of working code and are based on software development process models that support iterative, incremental development of software [12]. Delivering working software frequently is an important principle of the agile philosophy. Agile alliance principles also state that 'Business people and developers must work together throughout the project'. An important principle of the agile alliance is 'Welcome changing requirements even late in the project'. Thus all limitations of traditional techniques of datawarehousing can be addressed by the agile alliance principles. Following diagram shows how challenges of traditional techniques of datawarehousing can be addressed by agile principles.

\subsection{Past studies on agile Datawarehouse projects}

Requirements in Datawarehousing projects are difficult to elicit and evolve over a period. This is a reason why changing requirements is constantly highlighted as a major issue in datawarehousing projects.

Considering the difficulty of requirement elicitation and need to involve business users at various stages, a 'User driven requirement gathering technique' has evolved. In this technique of requirement gathering, emphasis is on approaches for facilitating user participation [17]. Though proponents of this technique do not label it as an agile methodology, but this methodology focuses on important agile principles like business people and developers working together, using face to face conversation for requirement elicitation.

Further to these early 'user focused' techniques, end to end methodologies leveraging agile principles have evolved. A design methodology called '4WD' has been proposed by applying risk based iterations, close user involvement, prototyping, component reuse, light documentation etc. [15].

In his book on agile analytics [18], Ken Collier has described application of agile principles and agile methodology to data warehousing and business intelligence projects. In this book, the author has stated that agile development is the single best risk mitigation approach. Also agile is the single best means of innovating high quality BI systems. In this book the author has described agile principles tailored for project management of Datawarehouse and Business Intelligence development. Also a detailed description of technical practices such as test driven development, version control, agile design are provided in this book.

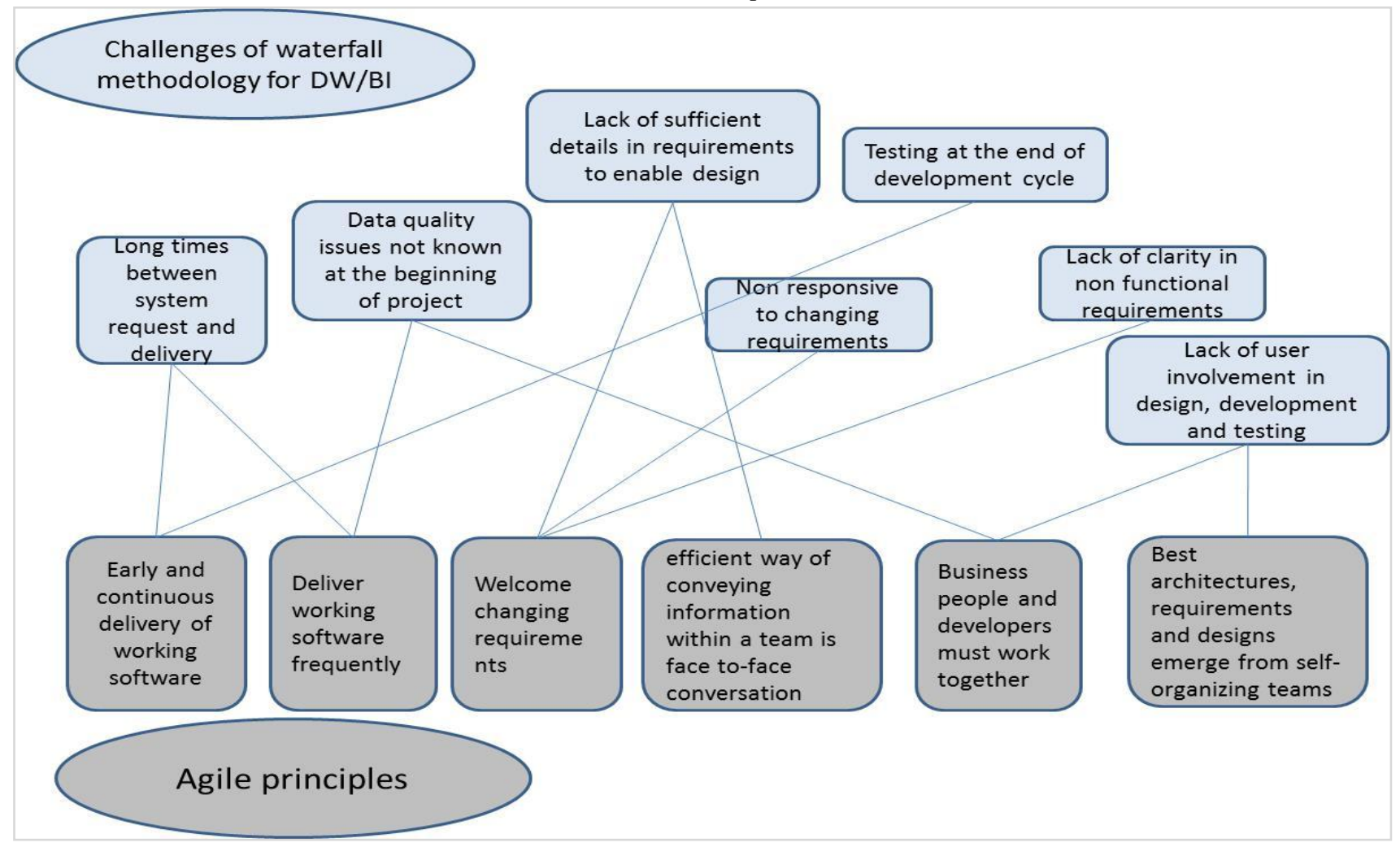

Figure 1: Challenges faced by Datawarehouse projects due to Waterfall

A detailed study of implementation of agile (Scrum) methodology for datawarehouse project has been conducted in [9]. This study has used action research methodology to analyze if scrum can be used for datawarehousing project. The researcher developed framework to evaluate how well the work was delivered by the project team using scrum. She developed a quality matrix to measure effectiveness of work delivered. The study concluded that the implementation of scrum for datawarehouse project failed. A detailed reasoning for the failure has been documented in this study.
Thus following is a summary about agile methodology for datawarehousing projects:

- Agile methodology has been deemed suitable for datawarehousing considering various aspects of datawarehousing such as uncertain requirements.

- There are studies published about failed implementations of agile datawarehousing. 
- Empirical evidence or guidelines do not exist about usage of agile methodology in datawarehousing projects.

\section{OBJECTIVES OF THE STUDY}

Although agile principles have elements that can be an answer to traditional issues in waterfall methodology, agile may not be beneficial in every situation. Various authors have cautioned about use of agile. Agile methods are not suitable everywhere due to some organizational and project environmental restrictions [2]. In [4,5] a study of reasons of failure of agile methodology is given. There is a lack of researches of suitability evaluations of agile methods considering various environmental characteristics at IT companies [2]. Especially very little empirical evidence and research is available for factors deciding suitability of agile methodology for datawarehousing projects. In [9] an action research on use of scrum for datawarehouse project has been presented. This study concludes that scrum methodology failed in some instances in the company, mainly due to people issues [9].

Proper use of agile processes requires an understanding of the situations in which agile processes are and are not applicable [12].

The main aim of this study is to develop a framework to determine whether a datawarehousing project is suitable to be executed using agile methodology or using waterfall methodology. The scope of this study is to evaluate agile methods in general and not any particular agile method. To help answer this question, following sub questions are formulated:

1. What are project characteristics that impact outcome of a Datawarehouse project executed using agile methodology?

2. What is the contribution of these project characteristics in positive or negative outcome of a datawarehouse project?

3. Based on the project characteristics is it possible to predict chances of success using agile or traditional waterfall methodology for a datawarehouse process?

The model will be empirically validated using real life project scenarios.

\section{FACTORS AFFECTING SELECTION OF AGILE FOR DATA WAREHOUSING PROJECTS}

In this section considerations for shortlisting factors that decide selection of methodology (agile / waterfall) for a datawarehouse project have been discussed.

\subsection{Study of Agile projects by Version One}

VersionOne conducts an annual survey of adoption and use of agile methodology [4,5]. One of the analyses done in this survey is reason for failed agile projects. Following table shows major reasons of failure of Agile project failure as discovered by these 2 surveys.
Table 1- VersionOne Agile Survey

\begin{tabular}{|l|l|l|l|}
\hline & $\begin{array}{l}\text { VersionOne } \\
\text { survey } \\
\text { 2012 }\end{array}$ & $\begin{array}{l}\text { VersionOne } \\
\text { survey } \\
\text { 2013 }\end{array}$ & \\
\hline $\begin{array}{l}\text { Total no. of } \\
\text { responses }\end{array}$ & $\begin{array}{l}\text { Total no. of } \\
\text { responses }\end{array}$ & $\begin{array}{l}\text { Combined } \\
\%\end{array}$ \\
\hline $\begin{array}{l}\text { Company philosophy } \\
\text { or culture at odds } \\
\text { with core agile values }\end{array}$ & 486 & 455 & $12.5 \%$ \\
\hline $\begin{array}{l}\text { External pressure to } \\
\text { follow traditional } \\
\text { waterfall processes }\end{array}$ & 445 & 350 & $10.5 \%$ \\
\hline $\begin{array}{l}\text { A broader } \\
\text { organizational or } \\
\text { communications } \\
\text { problem }\end{array}$ & 445 & 350 & $10.5 \%$ \\
\hline $\begin{array}{l}\text { Lack of experience } \\
\text { with agile methods }\end{array}$ & 364 & 385 & $9.9 \%$ \\
\hline $\begin{array}{l}\text { Lack of cultural } \\
\text { transition }\end{array}$ & 324 & 315 & $8.5 \%$ \\
\hline Other & 243 & 245 & $6.5 \%$ \\
\hline $\begin{array}{l}\text { Unwillingness of } \\
\text { team to follow agile }\end{array}$ & 243 & 245 & $6.5 \%$ \\
\hline $\begin{array}{l}\text { Lack of management } \\
\text { support }\end{array}$ & 243 & 245 & $6.5 \%$ \\
\hline Don't know & 162 & 175 & $5.5 \%$ \\
\hline Insufficient training & & & $3.5 \%$ \\
\hline New to agile & 243 & \\
\hline
\end{tabular}

\subsection{Principles for selection of methodology of software projects}

In a study about selecting a project's methodology, Alistair Cockburn has highlighted 4 fundamental principles that govern the selection of methodology [3].

As per this paper [3], following are fundamental principles:

1. A larger software development group needs a larger methodology

2. A more critical system one whose undetected defects will produce more damage needs more publicly visible correctness (greater density) in its construction.

3. A relatively small increase in methodology size or density adds a relatively large amount to the project cost.

4. The most effective form of communication (for transmitting ideas) is interactive and face-to-face, as at a whiteboard.

5. Project priorities (have the software soon, want it defect free, or want to have the process visible) decide methodology suitable for the project.

We leverage principles outlined by Cockburn for deciding factors that decide whether agile methodology is suitable for a datawarehouse project. Proposed model takes into account team size as a criterion for deciding suitability of agile. Larger team size should utilize traditional waterfall methodology. Also project priority has been taken into account for recommending appropriate methodology.

\subsection{Research on agile BI usage}

In [9] the author has conducted interviews of 9 interviewees who have used agile methodology for business intelligence. Interviewees were asked potential reasons for failure of agile 
business intelligence projects. Following reasons were stated by the interviewees:

\section{Environment (D1)}

- "Traditional mindset. Too many data professionals are stuck in 1970s thinking."

- "Lack of participation by the business people."

Management (D2)

- "Management won't commit to a firm feature set per sprint; therefore good deadlines won't be set."

- "Having developers run the projects instead of data management professionals."

Measurements (D3)

- "Measurements of project progress and success is measured still using traditional waterfall approach especially on completeness, where Agile is more flexible in terms of "completeness" due to its nature of using an iterative approach."

People (D4)

- "Poor skills. There is a very serious lack of testing skills, let alone database refactoring, test driven development, or other skills that are useful for agile"

- "Inexperienced project members concerning Scrumknow-how."

Processes (D5)

- "Not starting agile. Leaving agile to the development/testing and not applying it to analysis and design. It very difficult to go agile mid project."

Tools (D6)

- "Inmon or Kimball data modelling techniques, because they lead to data warehouses that cannot be easily redesigned for new requirements"

- "Heavy project administration."

\section{AHP PROCESS}

The question being investigated in this study is a structured decision problem. It requires prioritizing various project characteristics for their impact on success of the DW project.
One opportunity to prioritize different success variables, and obtain a ranking, is to use the analytic hierarchy process [21]. In AHP, factors impacting decision are arranged in a hierarchical structure descending from an overall goal to criteria, sub criteria and alternatives in successive levels [22]. Examples of usage of AHP can be found in evaluating project success criteria in software as well as construction industries $[21,2]$.

Steps recommended for AHP process are as follows [2]:

1. Arrange goals, attributes and issues in a hierarchy.

2. Perform pairwise comparison

3. Prepare comparison results and Estimate priority matrix

4. Perform accuracy check

5. Define generalized model

In remainder of this section, these 6 steps in AHP process are discussed.

\section{Arrange goals, attributes and issues in a hierarchy}

Most important task in the AHP process is to choose factors that are important for the decision [22]. Saaty has advised to select the factors as thoroughly as possible but not so thoroughly to lose the sensitivity to change in the elements [22].

For this study our goal is to assess suitability of BI projects that are suitable for agile implementation. Saaty has recommended that each hierarchy of the AHP problem should be a different 'cut' (i.e. way of looking) at the problem. 'Project characteristic category' is defined as an attribute of the goal. Hence our level 1 of the hierarchy is 'Project characteristic category'.

We further break down the project characteristics categories into more granular 'Project characteristics' which becomes level 2 of our hierarchy. For each project characteristics, 3 alternatives are considered. These alternatives are possible ways in which the characteristic can be implemented in a BI project. The alternatives become our level 3 of the hierarchy.

Figure 2 below shows the entire hierarchy.

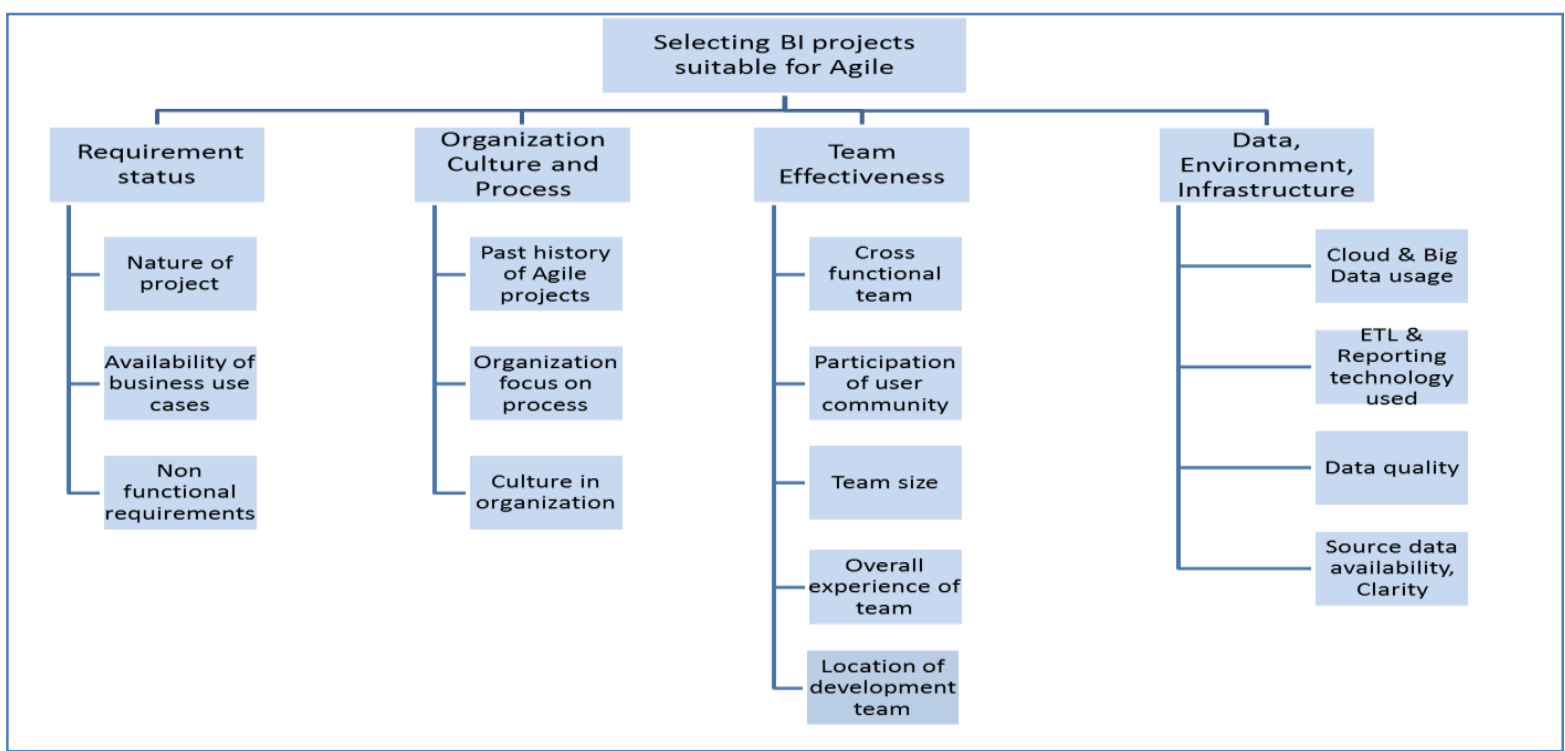

Figure 2- First 3 levels of Hierarchy 


\section{Perform pairwise comparison}

One of the important aspects of AHP is that it allows focusing judgement separately on each property essential for making the decision [22]. Fundamental scale used for pairwise comparison in this study is shown below:

Table 2- Scale for pairwise comparison

\begin{tabular}{|l|l|l|}
\hline $\begin{array}{l}\text { Relative } \\
\text { intensity }\end{array}$ & Definition & Explanation \\
\hline 1 & Equal value & $\begin{array}{l}\text { Two criteria are of equal } \\
\text { value }\end{array}$ \\
\hline 3 & $\begin{array}{l}\text { Slightly more } \\
\text { value }\end{array}$ & $\begin{array}{l}\text { Experience slightly favours } \\
\text { one criterion over another }\end{array}$ \\
\hline 5 & $\begin{array}{l}\text { Essential or } \\
\text { strong value }\end{array}$ & $\begin{array}{l}\text { Experience strongly favours } \\
\text { one criterion over another }\end{array}$ \\
\hline 7 & $\begin{array}{l}\text { Very strong } \\
\text { value }\end{array}$ & $\begin{array}{l}\text { A criterion is strongly } \\
\text { favoured and its dominance } \\
\text { is demonstrated in practice }\end{array}$ \\
\hline 9 & Extreme value & $\begin{array}{l}\text { The evidence favouring one } \\
\text { over another is of the } \\
\text { highest possible order of } \\
\text { affirmation }\end{array}$ \\
\hline $2,4,6,8$ & $\begin{array}{l}\text { Intermediate } \\
\text { values }\end{array}$ & $\begin{array}{l}\text { When compromise is } \\
\text { needed between 2 } \\
\text { judgments }\end{array}$ \\
\hline
\end{tabular}

Pairwise comparison for level 1 of the hierarchy (i.e. project characteristics categories) is shown in table below.

Table 3 - Pairwise comparison for level of Hierarchy

\begin{tabular}{|l|c|c|c|c|c|}
\hline Matrix & RS & OCP & TE & DEI & $\begin{array}{l}\text { Normalized } \\
\text { Principal } \\
\text { Eigenvector }\end{array}$ \\
\hline $\begin{array}{l}\text { Requirement status } \\
\text { (RS) }\end{array}$ & 1 & 1 & $1 / 3$ & 3 & $21.7 \%$ \\
\hline $\begin{array}{l}\text { Organization } \\
\begin{array}{l}\text { Culture and Process } \\
\text { (OCP) }\end{array}\end{array}$ & 1 & 1 & 1 & 5 & $31.8 \%$ \\
\hline $\begin{array}{l}\text { Team Effectiveness } \\
\text { (TE) }\end{array}$ & 3 & 1 & 1 & 3 & $38.2 \%$ \\
\hline $\begin{array}{l}\text { Data, environment } \\
\text { and infrastructure } \\
\text { (DEI) }\end{array}$ & $1 / 3$ & $1 / 5$ & $1 / 3$ & 1 & $8.3 \%$ \\
\hline
\end{tabular}

Similar pairwise comparison was performed for level 2 and level 3 of the hierarchy.

3. Prepare comparison results and prepare priority matrix -

We perform following steps to create results of comparison:

- Create the total of numbers in each column

- Divide each entry in the matrix by total of the column. This gives normalized values.

- Calculate average of each row to calculate Priority Matrix.

Following table shows normalized values and calculation of priority vector for level 1 matrix. Similar priority matrix calculation was done for all other pairwise comparisons. Please refer appendix for details of other priority matrix comparison.
Table 4 - Priority Vector for level 1 of Hierarchy

\begin{tabular}{|l|c|c|c|c|c|}
\hline $\begin{array}{l}\text { Normalized } \\
\text { Values }\end{array}$ & RS & OCP & TE & DEI & $\begin{array}{c}\text { Priority } \\
\text { Vector }\end{array}$ \\
\hline $\begin{array}{l}\text { Requirement status } \\
\text { (RS) }\end{array}$ & 0.19 & 0.31 & 0.13 & 0.25 & 0.219 \\
\hline $\begin{array}{l}\text { Organization } \\
\begin{array}{l}\text { Culture and Process } \\
\text { (OCP) }\end{array}\end{array}$ & 0.19 & 0.31 & 0.38 & 0.42 & 0.323 \\
\hline $\begin{array}{l}\text { Team Effectiveness } \\
\text { (TE) }\end{array}$ & 0.56 & 0.31 & 0.38 & 0.25 & 0.375 \\
\hline $\begin{array}{l}\text { Data, environment } \\
\text { and infrastructure }\end{array}$ & 0.06 & 0.06 & 0.13 & 0.08 & 0.083 \\
\hline
\end{tabular}

4. Perform accuracy check

The goal of this step is to calculate Consistency Index (CI) and Consistency Ratio (CR). Steps involved in this are as follows:

1. Multiply Priority Matrix with the priority vector. Resultant is called Consistency Measure (R)

2. Divide each element in $\mathrm{R}$ by corresponding element in priority vector to obtain Lambda.

3. Lambda Max is the average of all Lambda values.

4. Calculate Consistency Index $(\mathrm{CI})$ as $\mathrm{CI}=($ Lambda $\mathrm{Max}-\mathrm{N}) /(\mathrm{N}-1)$. In our case:

$\mathrm{CI}=(4.187-4) /(4-1)=0.062$

5. Look up value of Consistency measure in standard values. In this case $\mathrm{R}$ is 0.9

6. Calculate Consistency Ratio = Consistency Index / (Consistency Measure). In our case: $\mathrm{CR}=0.062 /$ $0.9=0.07$ i.e. $7 \%$. As a rule consistency ratio of 0.1 or less is considered acceptable. Hence in this case, the consistency check is valid.

Table 5 Consistency Measure for level 1 of Hierarchy

\begin{tabular}{|c|c|c|c|c|c|c|c|}
\hline & $\mathscr{\varkappa}$ & ఫે & $\underline{v}$ & 牙 & 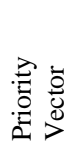 & 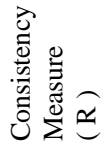 & 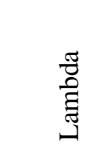 \\
\hline & \multicolumn{4}{|c|}{ Priority Matrix } & & & \\
\hline RS & 1.00 & 1.00 & 0.33 & 3.00 & 0.92 & 0.917 & 4.190 \\
\hline $\mathrm{OCP}$ & 1.00 & 1.00 & 1.00 & 5.00 & 1.33 & 1.333 & 4.129 \\
\hline $\mathrm{TE}$ & 3.00 & 1.00 & 1.00 & 3.00 & 1.60 & 1.604 & 4.278 \\
\hline DEI & 0.33 & 0.20 & 0.33 & 1.00 & 0.35 & 0.346 & 4.150 \\
\hline Sum & 5.33 & 3.20 & 2.67 & 12.0 & & & \\
\hline Avg & & & & & & & 4.187 \\
\hline
\end{tabular}

5. Define generalized model

Using the methodology described in section 1 to 4 above, pairwise comparison at each level of the defined hierarchy has been done. Generalized model after such pairwise comparisons is show below. 
Table 6 Generalized AHP Model

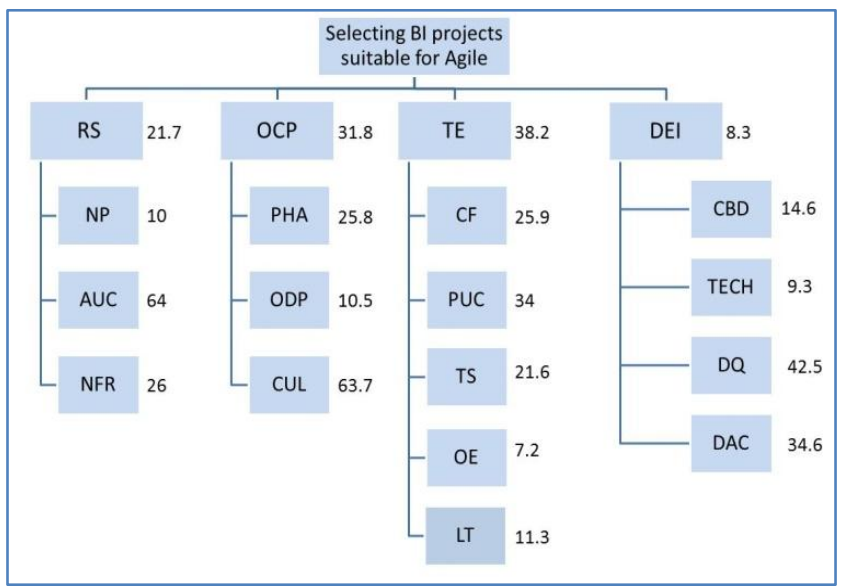

\section{ANALYSIS OF RESULTS}

From the model constructed above, it is clear that 5 most important factors in deciding whether a Datawarehouse project is suitable for agile model are as follows:

- $\quad$ Culture in the organization

- Participation of user community

- Cross functional team

- $\quad$ Team size

- Past history of Agile projects in the organization

It should be noted that most of the above factors are important for success of any IT project implemented using agile methodology. However, for Datawarehouse projects, three most important factors other than above listed generic factors are as follows:
- Data Quality

- Source system availability

- Non-functional requirements

More the ambiguity in source system data availability and data quality, more is the chance for the project to succeed using agile compared to using traditional waterfall methodology. Similarly more ambiguity in non-functional requirements leads to need for collaboration between IT and business for successful execution of Datawarehouse projects.

\section{USAGE OF CONSTRUCTED MODEL}

In this section the usage of constructed model for a real life case study has been demonstrated. This case study is for implementation of a datawarehouse for a banking organization. This project was estimated to be a 6 month effort. The project was executed using traditional waterfall methodology. Following is a summary of implementation approach, issues faced and prospects of using Agile methodology:

\subsection{Project Details}

Requirement in this project was to build a Datawarehouse for a banking organization. The bank had 24 different source systems that needed to be integrated in the Datawarehouse. Main aim of the project was to build a centralized data repository for decision making in the organization and replace the data silos in various parts of the organization. Original plan was to develop the Datawarehouse in 6 months.

A month long requirement gathering phase was planned followed by a development phase. The project team included about 20 developers out of which 5 had past experience in executing similar project for the banking domain. For more details of the project please refer Table 7 .

Table 7 - Application of assessment framework for a real life project

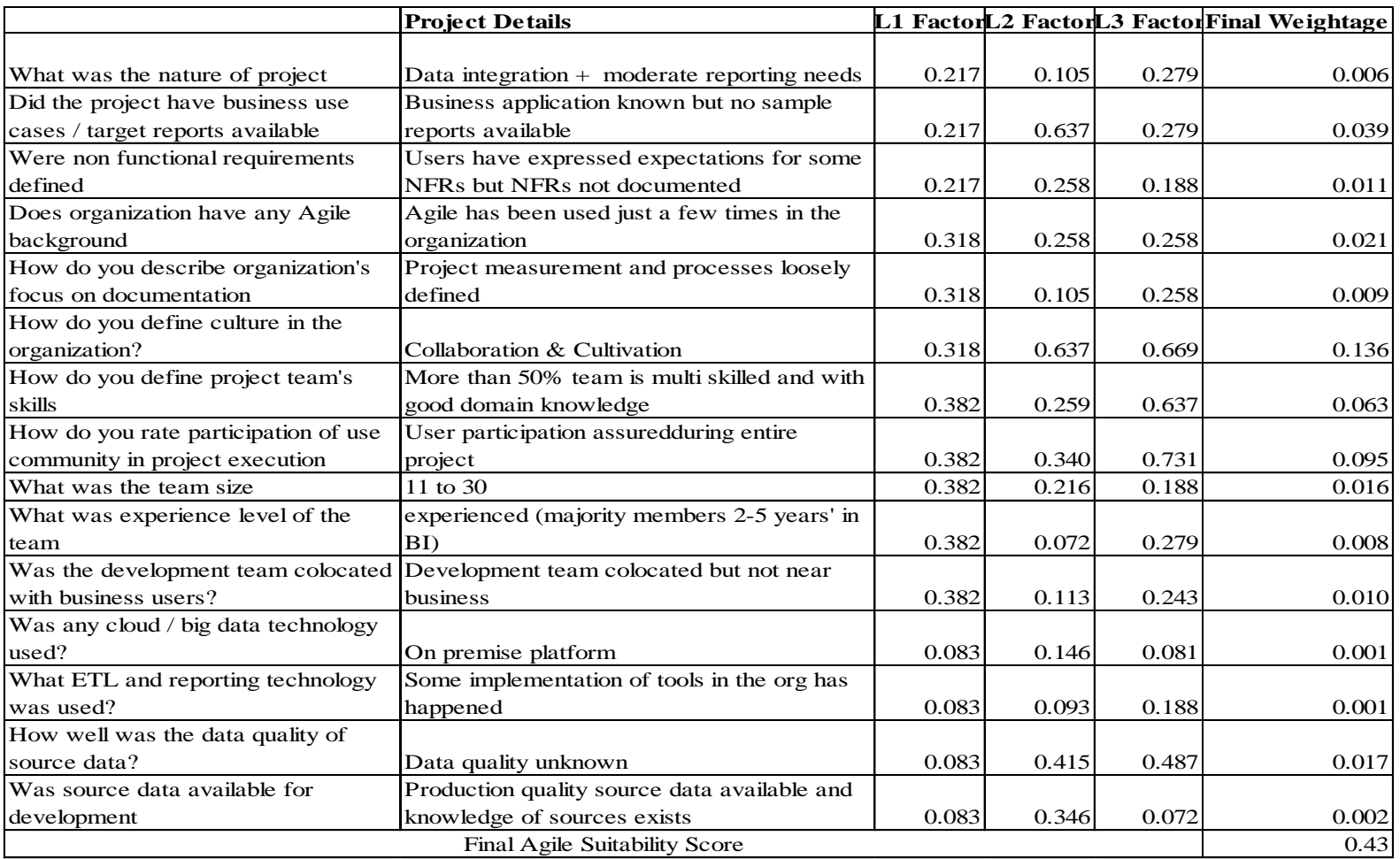




\subsection{Challenges Faced}

1. During the development phase numerous data quality issues were discovered. Also as the business users learnt more about the data, requirement changes kept on adding to the scope of the project. Thus the requirement phase extended to 2.5 months.

2. Sever data quality issues were found in the source system data during the course of the project and this derailed the development plan. Overall development was delayed to 6 months as against 4 months originally planned.

3. User acceptance testing was carried out with entire historical data and uncovered data patterns that were not discovered during the requirement or development phase. This needed changes to the design.

4. By the time the Datawarehouse was ready for production implementation, the project had exceeded its allocated time and budget. Also many of the business users had moved on to different roles. This reduced the relevance of the Datawarehouse to new business users.

5. After the implementation of the datawarehouse, its usage was very low due to changes in business requirements.

Overall the project was rated as a failure by the organization management. Delay in execution time, inability to meet changing business requirements and lack of flexibility were cited as reasons for treating the project as a failure.

\subsection{Evaluation of Agile}

Usage of agile methodology could have helped to avoid the failure of the project in following ways:

1. Early and frequent delivery could have ensured that the business users get access to some features of the datawarehouse in short time. This could have helped them use the datawarehouse and explain it to next set of business users.

2. Instead of spending high amount of time and money on implementing all planned features, business sponsor could have prioritized features and could have decided to implement only certain key features. This could have avoided cost and time overrun.

3. Close co-operation between business users and development team could have helped focus on changing requirements and discover data quality issues in time.

Teams involved in this project including the sponsor expressed using waterfall methodology as a main reason for the failure of the project. Table 7 describes the evaluation of the proposed model for this project. The model has calculated an agile suitability score of 0.43 for this project.

\section{CONCLUSION AND DIRECTIONS FOR FUTURE RESEARCH}

In this paper a model for assessment of suitability of agile methodology for datawarehouse projects has been developed. The model was applied for a real life project.

The model needs to be applied for more projects and results of the model should be correlated with actual outcome of the project. This exercise will lead to establishing a threshold Agile suitability score above which usage of Agile will result in higher changes of success.
Application of the model for datawarehouse projects during the planning phase will lead to higher changes of success for datawarehouse implementations.

\section{REFERENCES}

[1] Minna Pikkarainen, Ulla Passoja, An Approach for Assessing Suitability of Agile Solutions:A Case Study, Presented in XP 2005, 6th International conference of eXtreme Programming and agile process in software engineering. June 18-23, 2005

[2] G. Mikulenas, R. Butleris, An Approach for Constructing Evaluation Model of Suitability Assessment of Agile Methods using Analytic Hierarchy Process, Electronics \& Electrical Engineering;2010, Issue 106, p99, 2010

[3] Alistair Cockburn, Selecting a Project's Methodology, IEEE SOFTWARE, August 2000

[4] VersionOne, State of Agile Development, 7th Annual Survey, http://www.versionone.com/state_of_agile_development _survey/11/. Accessed Jan 2015

[5] VersionOne, State of Agile Development, 8th Annual Survey,

http://www.versionone.com/state_of_agile_development _survey/11/. Accessed Jan 2015

[6] R.W. van Dijk, Determining the Suitability of Agile Methods for a Software Project, 15th Twente Student Conference on IT, June 20th, 2011

[7] Mihaela MUNTEAN, Traian SURCEL, Agile BI - The Future of BI, Informatica Economica vol. 17, no. 3/2013

[8] D. Vavpotic, O. Vasilecas, An Approach for Assessment of Software Development Methodologies Suitability, Elektronika IR Elektrotechnika, 2011

[9] Susan, Mulder, An Approach for Assessment of Software Development Methodologies Suitability, University of Pretoria, 2010

[10] Chetankumar Patel. Muthu Ramachandran, Agile Maturity Model (AMM): A Software Process Improvement framework for Agile Software Development Practices, Int.J. of Software Engineering, IJSE Vol.2 No.1 January 2009

[11] Dave West and Tom Grant, Agile Development: Mainstream Adoption Has Changed Agility, January 20, Forrester, 2010

[12] Daniel Turk, Bernhard Rumpe, Assumptions Underlying Agile Software Development Processes, Journal of Database Management, 2003

[13] Tim Nugent et al, Business Intelligence and Data Warehousing Taking an agile approach to implementation,http://www2.deloitte.com/content/dam/D eloitte/au/Documents/technology/deloitte-au-techbusiness-intelligence-data-warehousing-161014.pdf, accessed February 2015

[14] Kuldeep Deshpande, Bhimappa Desai, A Critical Study of requirement gathering and testing techniques for datawarehousing, INTERNATIONAL JOURNAL OF INFORMATION TECHNOLOGY \& MANAGEMENT INFORMATION SYSTEM, April 2014 
[15] Matteo Golfarelli, Stefano Rizzi, and Elisa Turricchia, Modern Software Engineering Methodologies Meet Data Warehouse Design: 4WD, Springer-Verlag Berlin Heidelberg, 2011

[16] Deanne Larson, BI Principles for Agile Development: Keeping Focused, BUSINESS INTELLIGENCE JOURNAL VOL. 14, NO. 4, 2010

[17] Matteo Golfarelli, From User Requirements to Conceptual Design in Data Warehouse Design - a Survey, Data Warehouse Design and Advance Engineering Applications: Methods for Complex Construction; 2010: 1

[18] Ken Collier, Agile Analytics-A value driven approach to business intelligene and data warehousing 1st Edition, Addison-Wesley, 2011

[19] Petr

Podrouzek, https://www.linkedin.com/pulse/20140916184627- 77036555-agile-bi-series-1-13-agile-for-bi-is-

recommended-by-the-experts-but-is-it-used-in-the-realworld?trk=mp-author-card\&trk=mp-author-card, Accessed April 2015

[20] Afshin Pakseresht , Dr. Gholamreza Asgari, Determining the Critical Success Factors in Construction Projects: AHP Approach, INTERDISCIPLINARY JOURNAL OF CONTEMPORARY RESEARCH IN BUSINESS, Vol 4, 2012

[21] C. Wohlin and A. Andrews, "Prioritizing and Assessing Software Project Success Factors and Project Characteristics using Subjective Data", Empirical Software Engineering: An International Journal, Vol. 8, No. 3, pp. 285-308, 2003

[22] Thomas Saaty, How to make a decision: The analytical hierarchy process, European Journal of Operational Research, 1990 